\title{
STUDY OF COLOUR CHANGE IN THE COURSE OF DRYING ON PRINTS CREATED USING OFFSET PRINTING TECHNOLOGY
}

\author{
Csaba Horvath (D), Pál Görgényi-Tóth \\ Óbuda University, Institute of Media Technology and \\ Light Industry Engineering, Budapest, Hungary
}

\begin{abstract}
The research presented in the article describes the colour changes resulting from the drying of printing ink. In technical terminology, this colour change is called dryback (Schulz et al, 2005). Different print technologies use different inks (solvent-based, inks dried by oxidation, inks dried by UV radiation), but all of them are affected by dryback. This means that the ink still wet after printing has colour properties different from ink after it is dried. During the printing process it is usually possible to measure the colour properties (lightness, blue-yellow, red-green content, density) of the still wet print by the machine. A polarizing filter is installed in spectrophotometers in order to perform this measurement, which tries to measure the colour characteristics of the print, eliminating surface reflection. The research is designed to determine the point when the paint can be considered dried on the carrier (paper), to describe - using mathematical equations - the changes in the colour characteristics during the drying process, and then to design a device which is able to determine - using the mathematical model - what colour characteristics the still wet print will have after complete drying. In our article we intend to describe the first tests and the resulting conclusions.
\end{abstract}

Key words: printing inks, carrier drying, autotype prints, density, colour stimulus difference, colour change

\section{OBJECTIVES OF THE RESEARCH}

Industrial printing inks solidify on the paper through various drying mechanisms. There are differences between the dying processes of the 'classic' ink dried by oxidation, a solvent based ink, and an ink dried by UV radiation. In the case of offset technology, ink drying is a complex process. Polymerization caused by oxidation (that is why prints are powdered in case of sheetfed offset ink; due to their size, the particles create an air vent between two sheets, allowing free airflow between the sheets), evaporation (for example gravure or flexo ink), and penetration (ink of cold-set printing dries this way) also play their part in the process of drying (INKFORMATION, 2011). As experience shows during the drying process, different values in terms of color characteristics (density, color stimulus difference) are shown once ink has fully dried on the paper, as compared to color characteristics measured right after printing. This phenomenon is called back-drying (Şahinbaskan et al, 2010). Factors influencing the ink drying process:

- additives in the ink containing dryers,

- ink viscosity,

- quantity and quality of the lubricant used during printing,

- ambient air temperature,

- ambient air humidity,

- paper surface,

- paper volume and aA value,

- air flow (oxygen concentration changes in case of air flow).

In our research the role of these factors within the drying process was examined. That is, only those ones of these parameters that can be changed. We intend to measure colour changes during drying after as many ways of modifications as possible.

Our goal is to define the change based on the exact measurements of a mathematical model, to develop a software for the existing measuring devices (densitometer, spectrophotometer) using an algorithm based on the mathematical model, or to make a new measuring device. This software could be used to determine the post-drying color characteristics of a specific color in the printing stage, in order to achieve the original colors of the sample after the dryback of the wet print.

For the research, we have defined three phases of the experiments. The first series of experiments are carried out in a laboratory, while the pilot measurements in the second phase of the experiment are 
intended to confirm the results of the laboratory tests. The third step is the production trial, where our results are confirmed or adjusted in operational conditions.

We have selected offset printing for the measurements made in pilot and operational conditions. This is the technology, where the ink used dries in the most complex way, and colour change is also the most striking here. Offset printing is the most complex printing technology: liquid lubricant is necessary for the selectivity of the image areas and the non-image areas, and rheometer data (viscosity, tack value) must be changed in order to make the ink suitable for printing.

To conduct the experiments, from among the papers most frequently used in the printing industry, we selected 3 different print media types of the same square meter weight $\left(100 \mathrm{~g} / \mathrm{m}^{2}\right)$, however of different structure and characteristics:

- offset (uncoated)

- glossy paper (coated)

- $\quad$ and optical bleach-free paper.

The measurements were started with the 4 colours [Cian, Magenta, Yelow and Black (Key)] of autotype printing, since these are the colours typically used for colour printing. These four colours are used for determining the mathematical correlations, and later the basic colours of the direct colours are used for the checking and correction of the mathematical formula.

The first phase of the experiments was conducted at the Hungarian company of Sun Chemical Corporation, where the color changes of the printed inks were modeled and measured with ink testing instruments under laboratory circumstances. At first, the temporal changes of colors were recorded under the specific circumstances of temperature and humidity. Density and hues of each sample are $\left(L^{*}, a^{*}, b^{*}\right)$ measured, then they are calculated according to the colour stimulus difference contained in the excel table included in the publication (Sharma et al, 2005).

\section{RESEARCH METHODS}

IGT C1 Offset and Letterpress Proofer Series test printing machine was used for the basic experiments conducted in the ink laboratory (Figure 1).

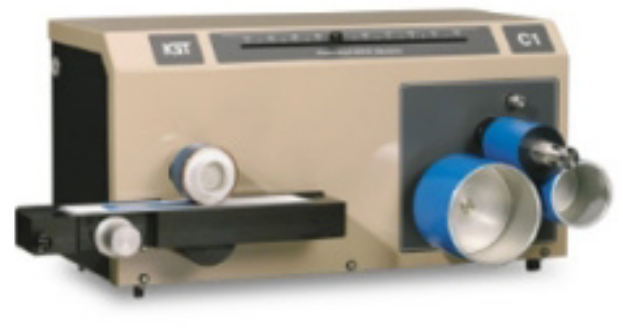

Figure 1: IGTC1

The test strip printed with the test printing machine represented the measurement fields with $100 \%$ fill ratio. The inks of Sunchemical SunLit Intense Process were used for the tests with all the three selected carriers. Rheometer data of the inks are shown in Table 1.

Table 1: Data of the examined inks

\begin{tabular}{|c|c|c|c|c|c|c|}
\hline & INT09 & INT41 & INT39 & INT38 & INT24 & INT75 \\
\hline $\begin{array}{c}\text { Viscosity Rheometer } \\
\text { 50s-1, 23-C (Pa.s) }\end{array}$ & $45-60$ & $45-60$ & $70-90$ & $75-95$ & $42-55$ & $42-55$ \\
\hline $\begin{array}{c}\text { Yield value Rheometer } \\
\text { 2s-1, 23-C (Pa.s) }\end{array}$ & $65-120$ & $65-120$ & $90-170$ & $90-170$ & $60-100$ & $55-100$ \\
\hline $\begin{array}{c}\text { Tack Thring Albert } \\
\mathbf{8 0 0} \text { rpm (g.m) }\end{array}$ & $7,5-10,5$ & $7,5-10,5$ & $8,5-11,5$ & $9-12$ & $8,5-11,5$ & $8,5-11,5$ \\
\hline
\end{tabular}


Ink density was set to similar values in the case of all carriers (in the case of coated paper: $D C=1.5$, $D M=1.6, D Y=1.4, D K=1.5$, uncoated paper: $D C=1.45, D M=1.45, D Y=1.25, D K=1.45$, and bleach-free paper: $\mathrm{DC}=1.5, \mathrm{DM}=1.6, \mathrm{DY}=1.4, \mathrm{DK}=1.6)$.

The colours were measured with X-Rite eXact type spectrophotometer (device settings: D50 and 45/0 diffuse illumination, $2^{\circ}$ viewing angle, without $M 1$ filter). The measurements were based on measuring the colours $L^{*}, a^{*}, b^{*}, L^{*}, C, H, X, Y, Z$ and the density values. Device repeatability was $0.01-0.02$.

Based on the continuous measurement of the air temperature and relative humidity in the measurement room, it can be concluded that both the temperature and the humidity were constant during the measurement (the temperature was $25^{\circ} \mathrm{C}$, while relative humidity was $48 \%-52 \%$ ).

\section{SUMMARY OF THE RESULTS}

During the measurements, the changes in the colour components were measured through one hour, then the measurements were repeated after a few days (when the ink was expected to be completely dry) in order to compare the previous values to the values of the completely dry ink colours. We also intend to perform the examination of the ink drying process in order to determine when an ink layer can be considered completely dry, and no further colour change can be expected. (note to X-Rite company: it would be nice to design an application allowing measurement intervals for automatic measurement, so that measurements could be made for 24 or even 48 hours in every fifteen minutes.)

The changes are illustrated in diagrams as well, and the diagrams include the formula of the function best fitting the curve, as well as its regression. The regression values are almost always 98-99, which means that the calculated curve fits the measured data. When illustrating the brightness values versus time, the following changes were noticed (Figures 2-4):
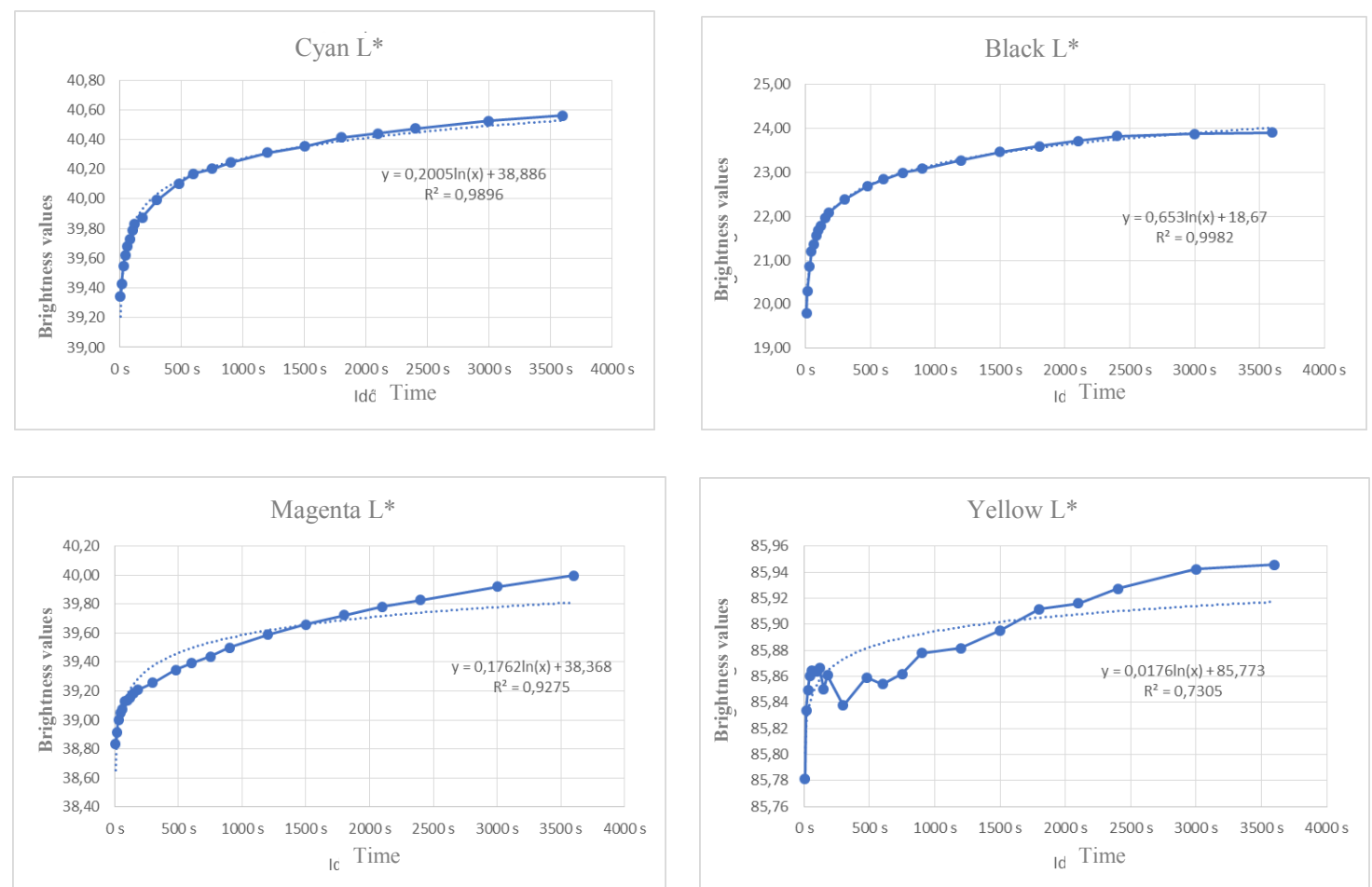

Figure 2: Brightness values in case of bleach-free paper 

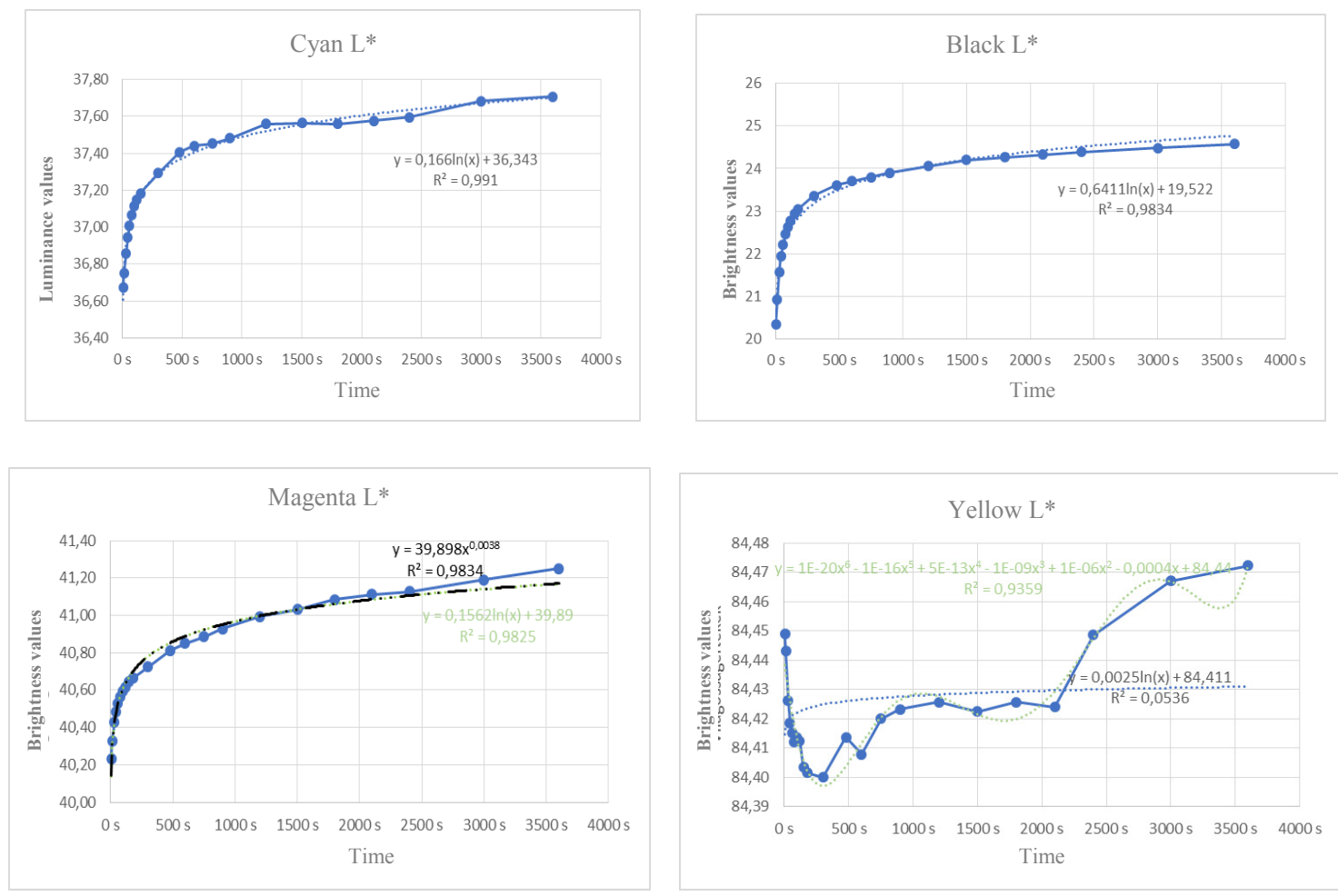

Figure 3: Brightness values in case of uncoated paper
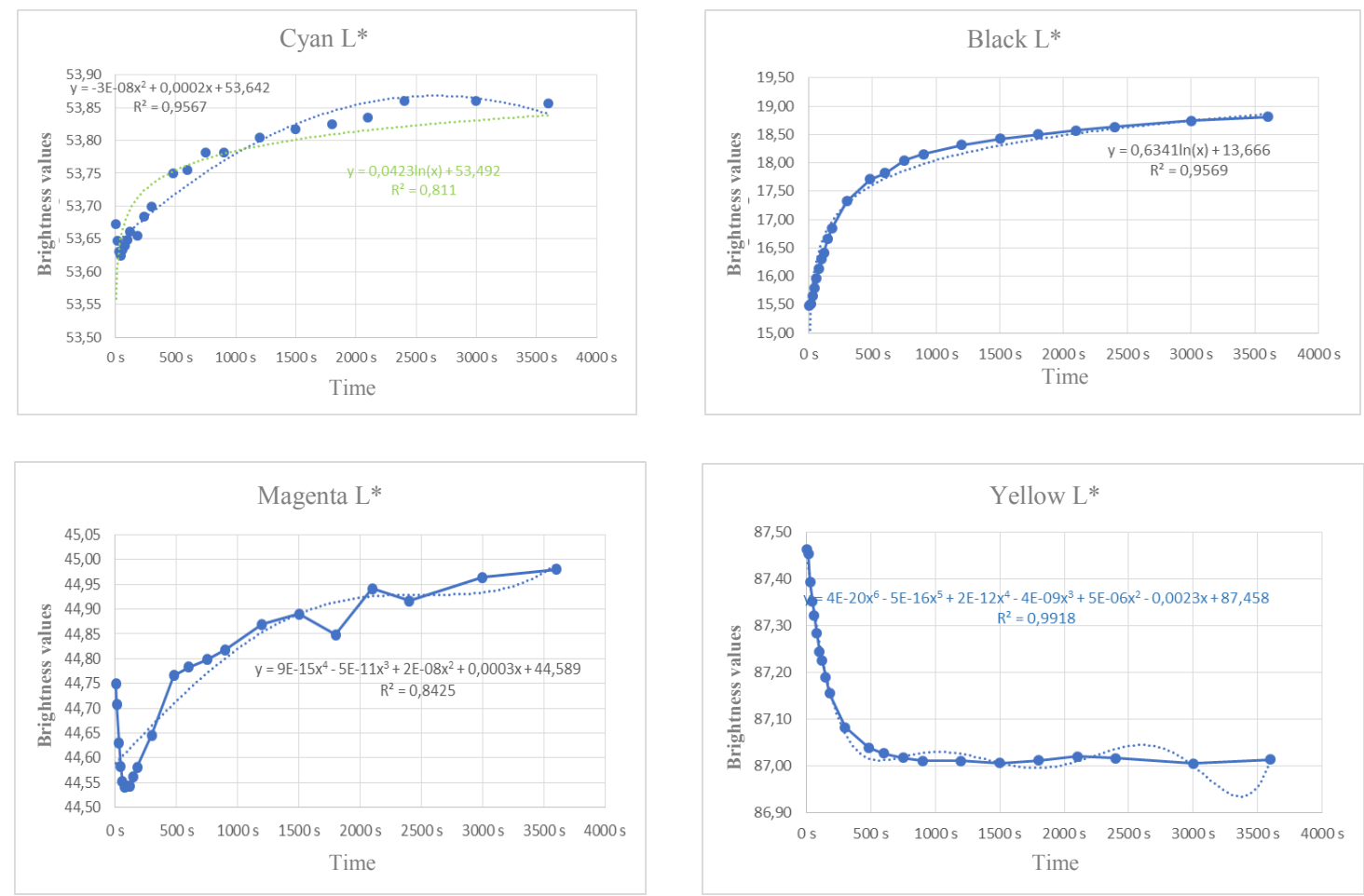

Figure 4: Brightness values in case of coated paper

In the large part of the measurements the brightness values changed versus time, according to a natural logarithm function. The exceptions were: yellow colour in case of coated and uncoated papers, and magenta as well in case of coated papers.

The colour changes measured on $a^{*} b^{*}$ plane are shown in Figures $5-7$. (The time of the measurement is indicated on the measurement points to identify the curve changes). 

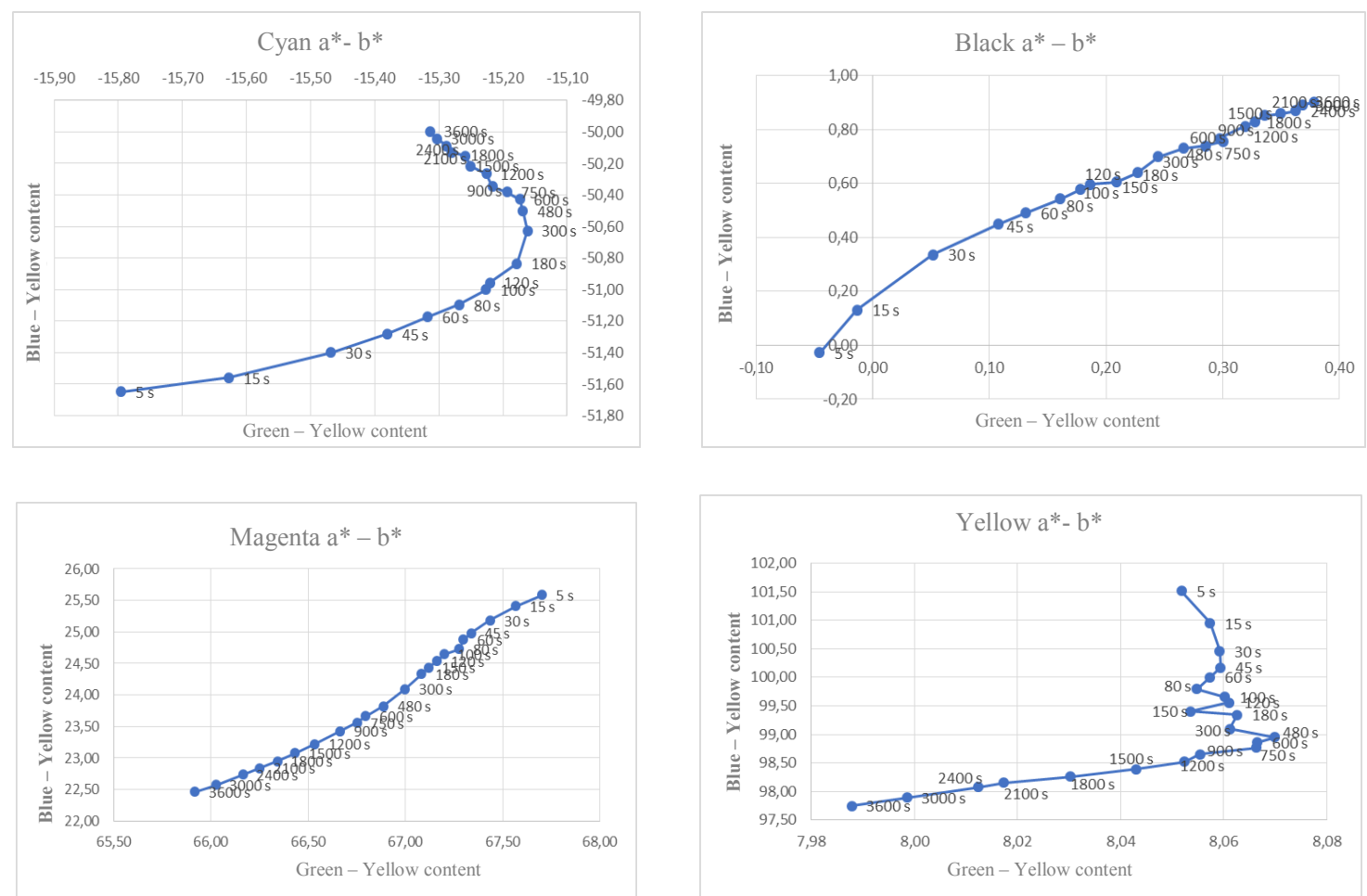

Figure 5: Changes shown in $a^{*}-b^{*}$ plane in case of bleach-free papers
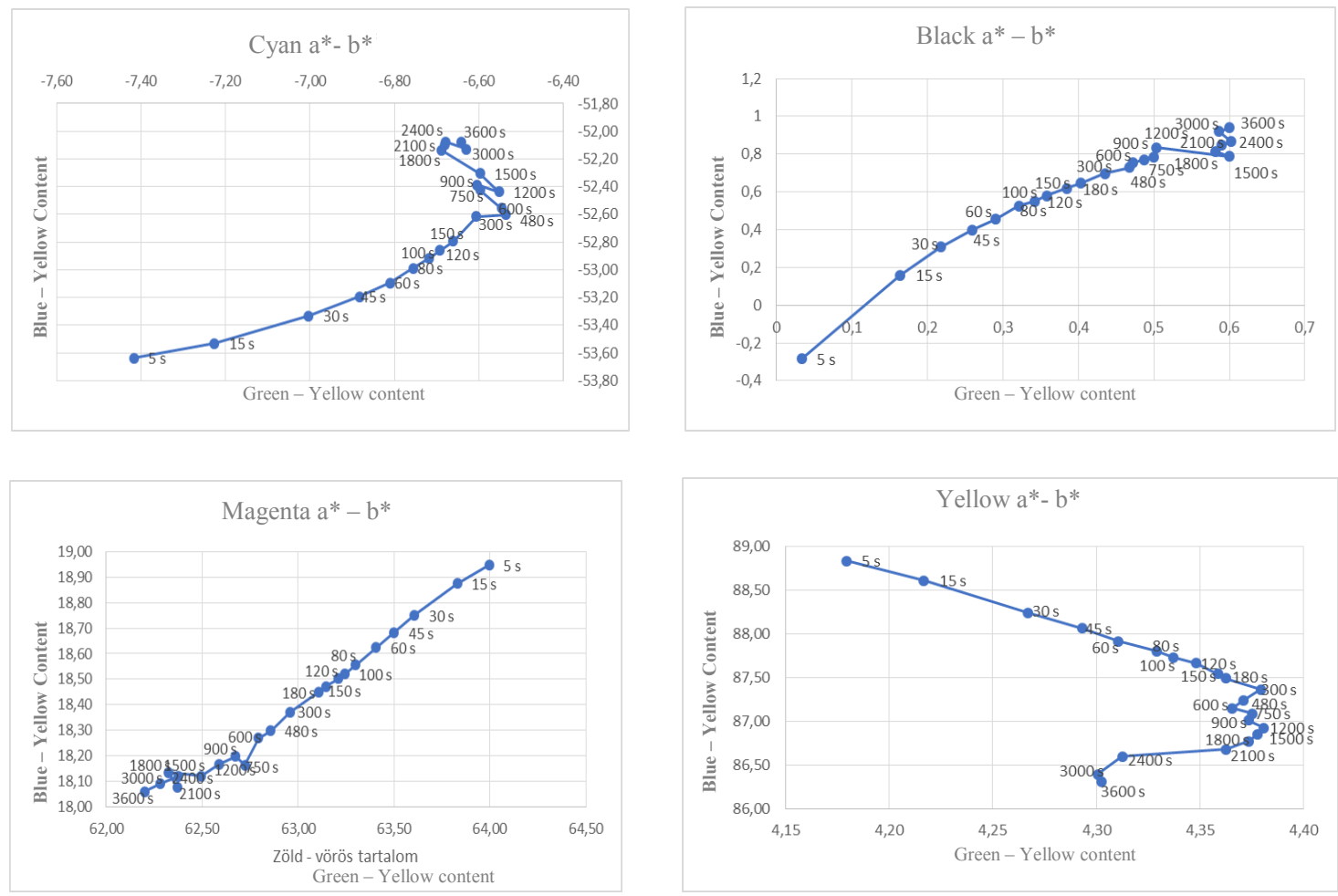

Figure 6: Changes shown in $a^{*}-b^{*}$ plane in case of uncoated papers 

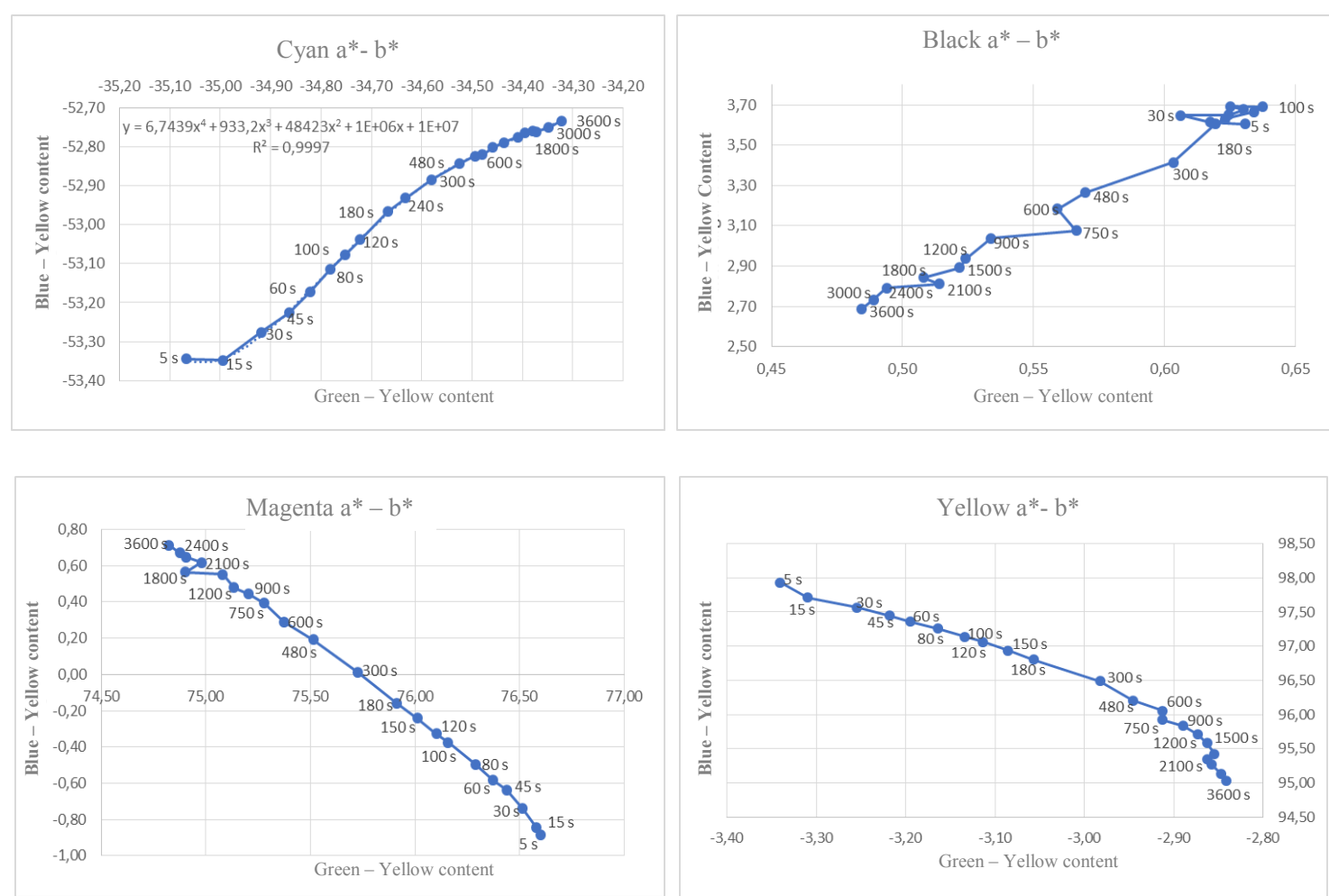

Figure 7: Changes shown in $a^{*}-b^{*}$ plane in case of coated papers

In case of all paper types the blue - yellow content of cyan colour shifted towards the blue, while in case of green - red content it shifted towards the red. The colour of cyan ink shifted towards the reddish blue in case of all paper types. Magenta shifted towards the yellow and the red, and when it was used on coated paper, it shifted towards the blue. In case of all the three paper types the black colour showed monotone increase towards yellow - red, so the colour got darker.
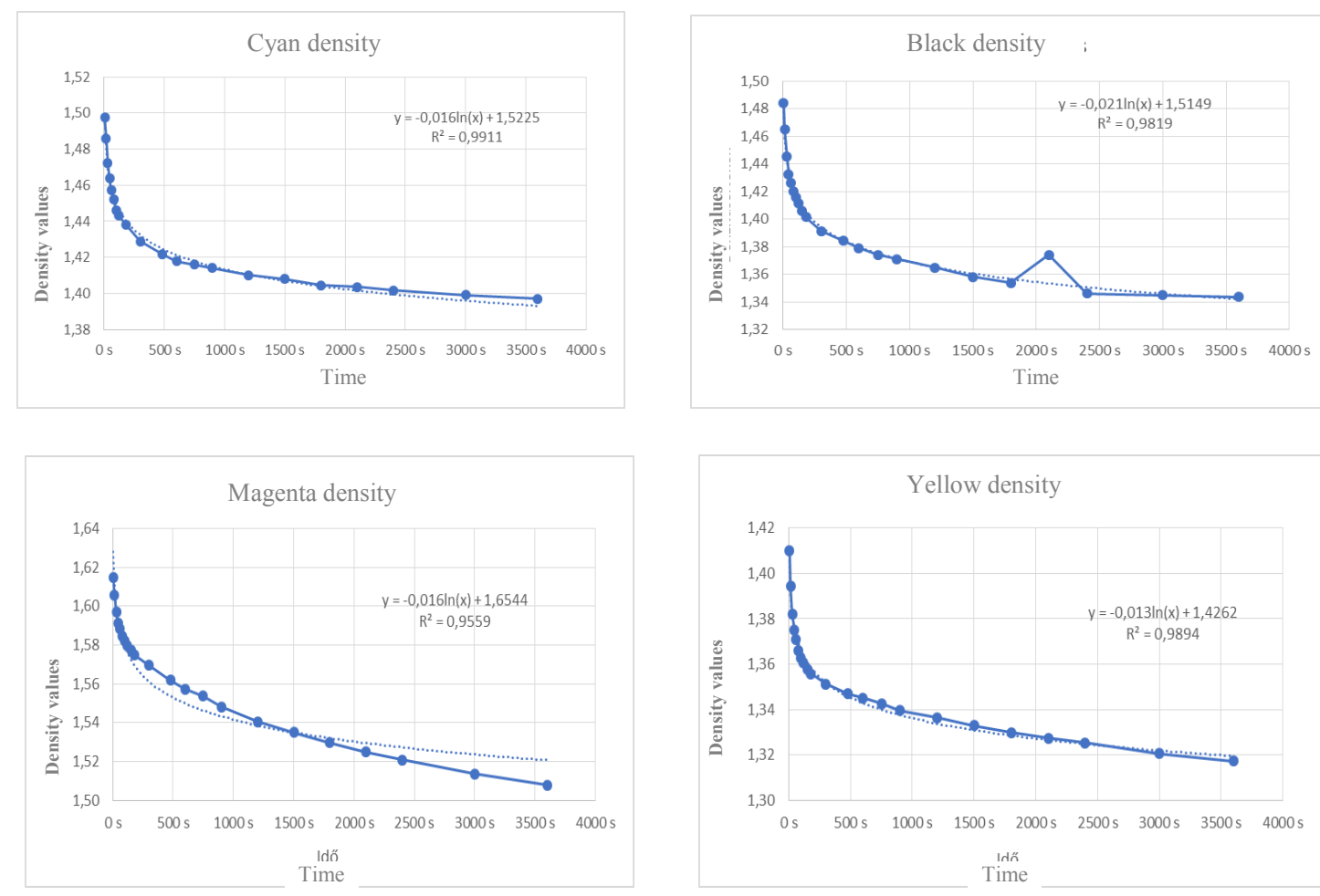

Figure 8: Density changes in case of bleach-free papers 
In case of all the three paper types yellow changed differently during the drying process; yellow shifted towards green, red shifted towards blue, while blue shifted towards green.
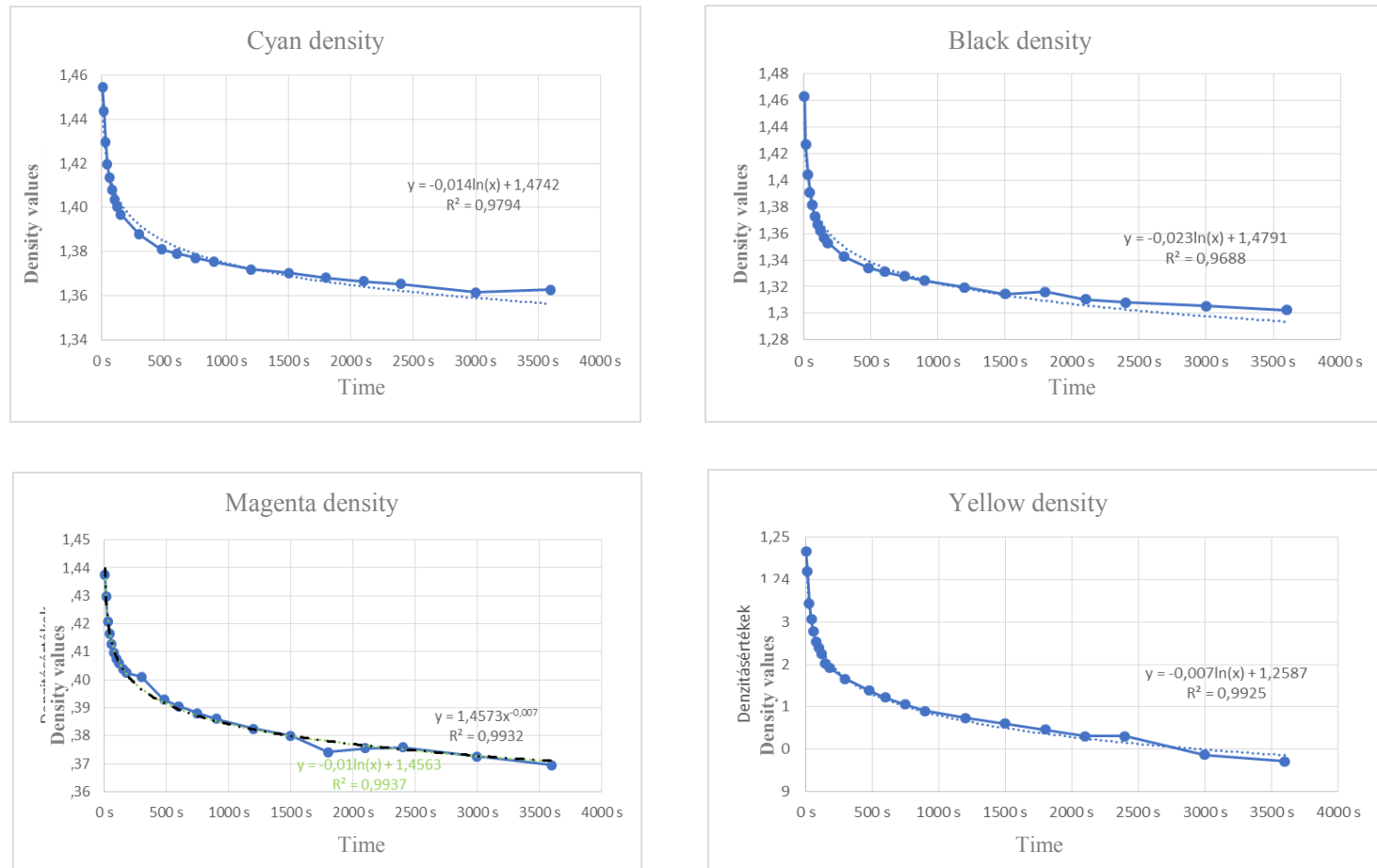

Figure 9: Density changes with uncoated papers
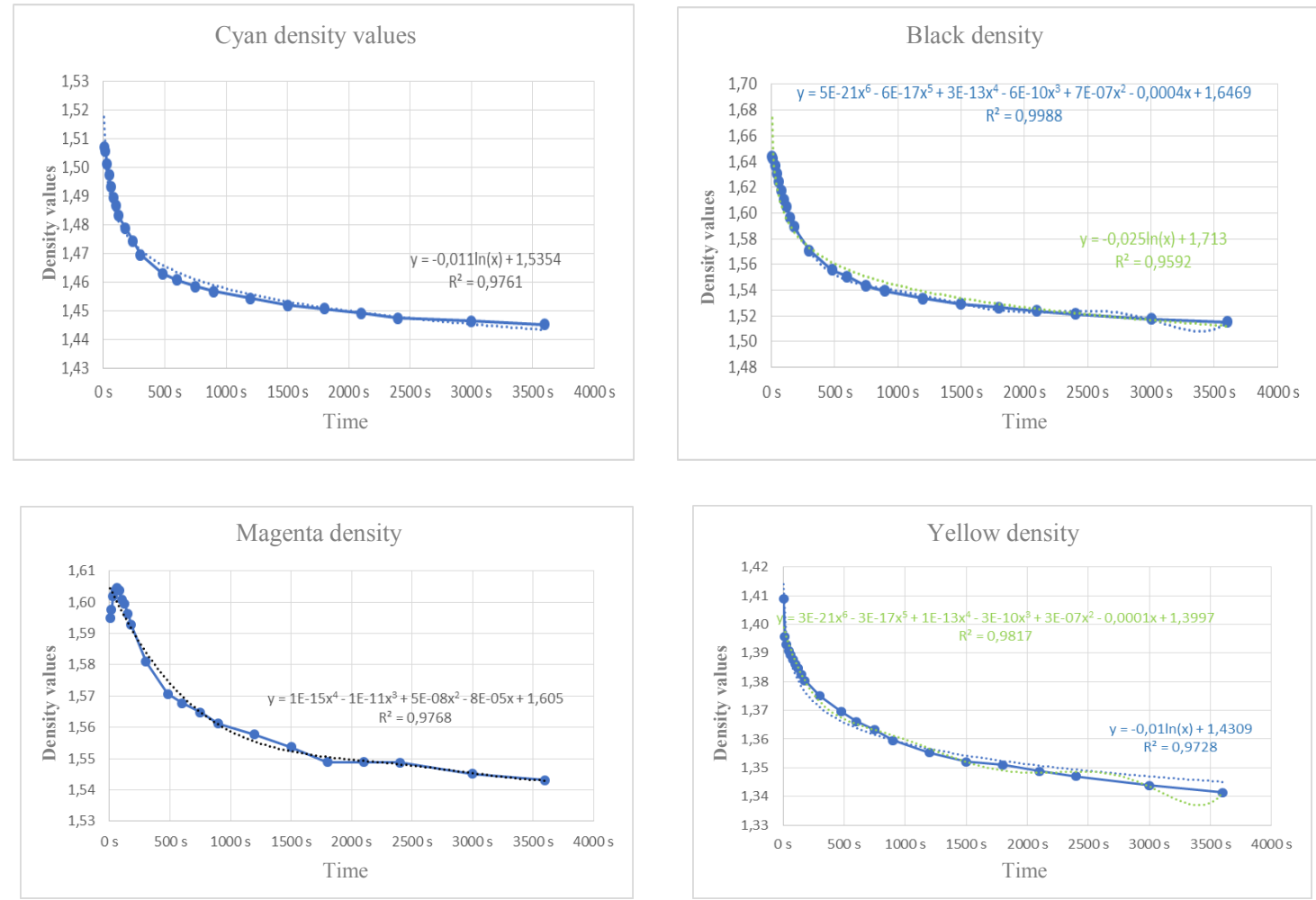

Figure 10: Density changes in case of coated papers

The curves of the density values are monotonous decreasing, following natural logarithm (at some points n-degree polynomial) function, growing fast up to 500s, then slowing down. This is due to the in reflection of the red paint, which can be eliminated by polarization filter. 
After a certain period of time (3-4 days later) the ink was totally dry. At this point we repeated the measurements on the colour components, and with the use of the method mentioned above we calculated the colour stimulus difference between the colour of the dry ink and the ink in the drying process. The results are shown in Figures 11-13:
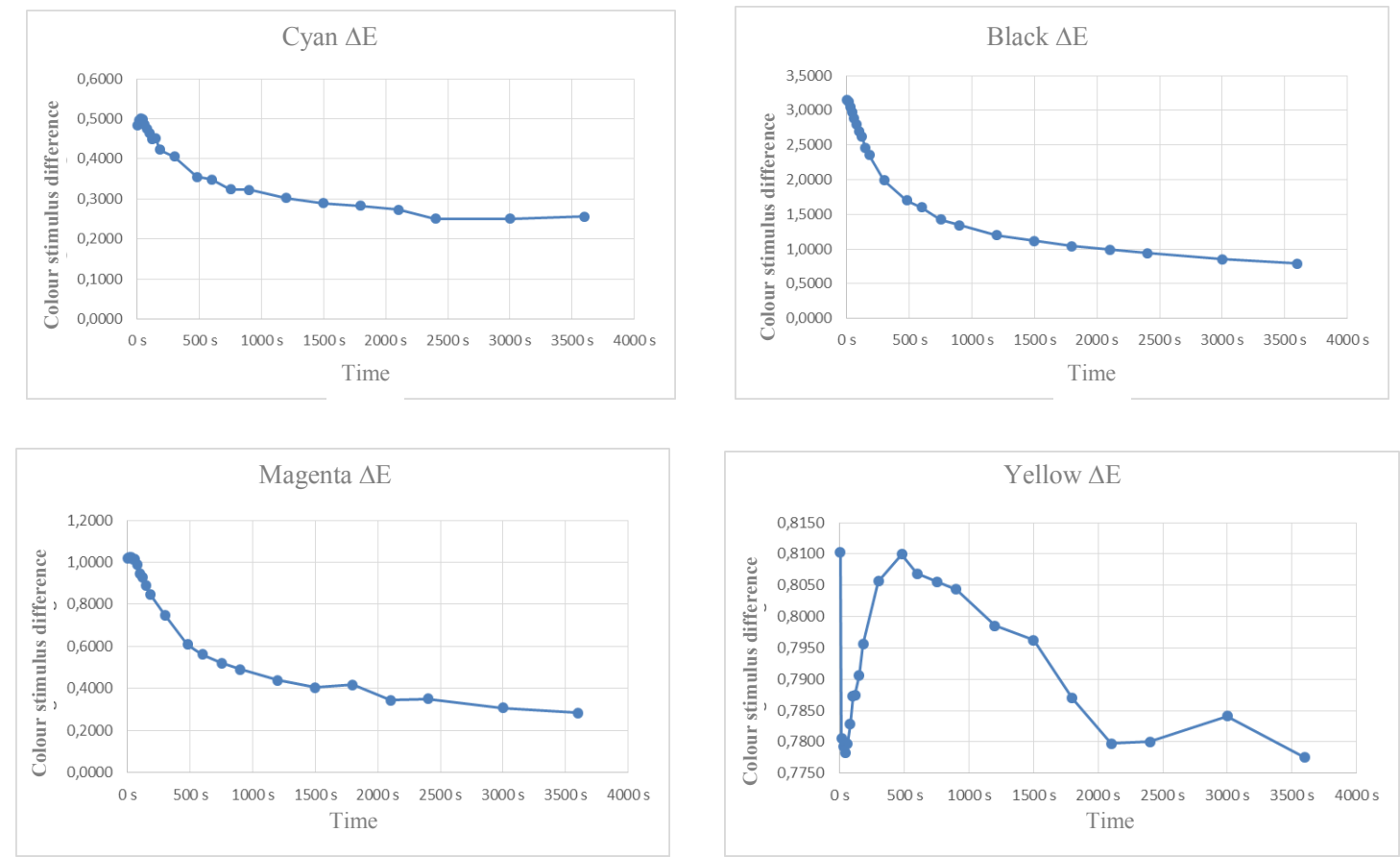

Figure 11: Changes in colour stimulus difference in case of coated paper
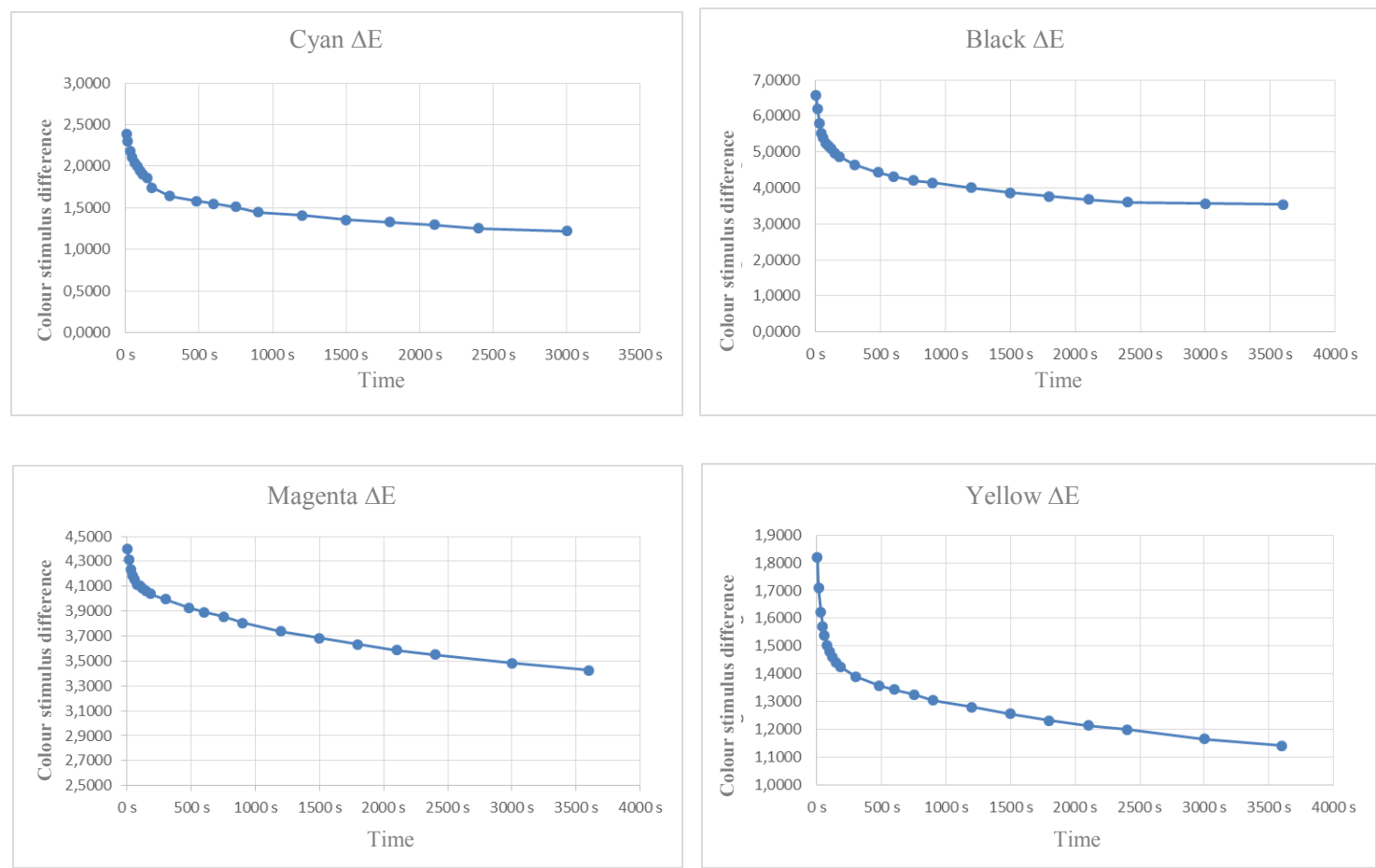

Figure 12: Changes in colour stimulus difference in case of bleach-free paper 

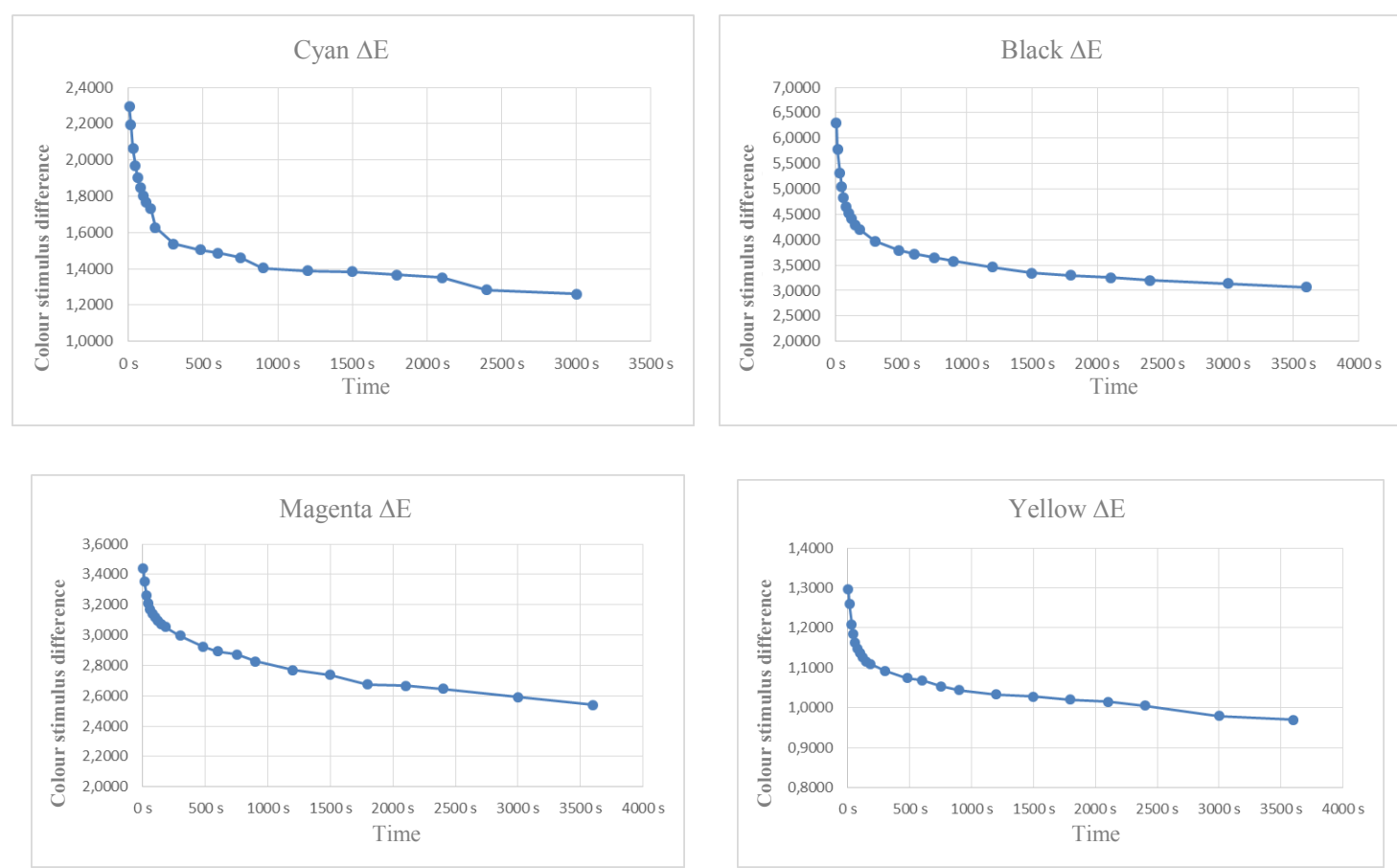

Figure 13: Changes in colour stimulus difference in case of coated paper

The colour stimulus difference calculations clearly show the trend of drying, that is - although none of the inks reached the final colour on paper - the colour stimulus difference between the colours is smaller and smaller. It is also true to these diagrams that the changes are faster during the first 500 seconds, and as the ink starts to dry, the $\Delta \mathrm{E}$ change gets slower as well.

\section{CONCLUSION}

During our research we have found that ink colour change appearing on the paper follows the same curves (except for a few cases), and the colour is changed similarly over time on the same type of paper. The colour stimulus difference of completely dry ink changes following the same trend (monotonous decrease), only the magnitude of the difference varies.

In pilot plant trials we continue examining the functions describing differences and changes. In addition to examining colour and density values, we intend to examine changes in the colour angles, in brightness, therefore each variable parameter mentioned at the beginning of this article will be changed. By way of rubbing we will experiment the exact time when an ink can be considered dry, and we will draw further conclusions later.

\section{REFERENCES}

[1] INKFORMATION, Test methods for offset inks and substrates, Huber Group, 2011. URL: http://www.hubergroup.net/pdf-files/inkformarion/INKFORMATION_4_en_02.pdf (last request: 2018-10-24)

[2] Şahinbaşkan, T., Köse, E.: "Modelling of time related drying changes on matte coated paper with artificial neural networks", Expert Systems with Applications, 37 (4), 3140-3144, 2010. doi: 10.1016/j.eswa.2009.09.068

[3] Schulz, P., Endrédy, I.: "Angol-magyar nyomdaipari értelmező szótár", Mérnök és Nyomdász Kft., Budapest, 2005

[4] Sharma, G., Wu, W., Edul, N. D.: "The CIEDE2000 color-difference formula: Implementation notes, supplementary test data, and mathematical observations", Color Research \& Application, 30 (1), 21-30, 2005. doi: 10.1002/col.20070 


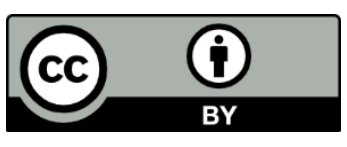

(C) 2018 Authors. Published by the University of Novi Sad, Faculty of Technical Sciences, Department of Graphic Engineering and Design. This article is an open access article distributed under the terms and conditions of the Creative Commons Attribution license 3.0 Serbia

(http://creativecommons.org/licenses/by/3.0/rs/). 